\title{
Evaluation of Lettuce Germplasm Resistance to Gray Mold Disease for Organic Cultivations
}

\author{
Chang Ki Shim, Min Jeong Kim*, Yong Ki Kim and Hyeong Jin Jee \\ Organic Agriculture Division, National Academy of Agricultural Science, RDA, Suwon 441-707, Korea
}

(Received on July 1, 2013; Revised on November 12, 2013; Accepted on November 21, 2013)

This study was conducted to evaluate the resistance of 212 accessions of lettuce germplasm to gray mold disease caused by Botrytis cinerea. The lettuce germplasm were composed of five species: Lactuca sativa (193 accessions), $L$. sativa var. longifolia ( 2 accessions), $L$. sativa var. crispa (2 accessions), $L$. saligna (2 accessions), and $L$. serriola (1 accession); majority of these originated from Korea, Netherlands, USA, Russia, and Bulgaria. After 35 days of spray inoculation with conidial suspension $\left(3 \times 10^{7}\right.$ conidia/ $\left./ \mathrm{ml}\right)$ of $B$. cinerea on the surface of lettuce leaves, tested lettuce germplasm showed severe symptoms of gray mold disease. There were 208 susceptible accessions to $B$. cinerea counted with $100 \%$ of disease incidence and four resistant accessions, IT908801, K000598, K000599, and K021055. Two moderately resistant accessions of $L$. sativa, K021055 and IT 908801 , showed $20 \%$ of disease incidence of gray mold disease at $\mathbf{4 5}$ days after inoculation; and two accessions of $L$. saligna, K000598 and K000599, which are wild relatives of lettuce germplasm with loose-leaf type, showed complete resistance to $B$. cinerea. These four accessions are candidates for breeding lettuce cultivars resistant to gray mold disease.

Keywords : genetic resources, Lactuca sativa L., Lactuca saligna L., Botrytis cinerea, tolerance

In organic farming systems, the cultural management practices play a vital role in disease management techniques. Planting materials should be clean, vigorous and pathogenfree; and transplanting should be maintained at the best possible growing conditions. Varieties chosen should be disease-resistant and effective disease control management of Botrytis cinerea in lettuce production in the greenhouse

*Corresponding author.

Phone) +82-31-290-0545, FAX) +82-31-290-0507

E-mail)kjs07@korea.kr should be applied (Hornby, 1990; Seaman et al., 2012).

In Korea, leaf lettuce is commonly used as wrap-up vegetable and as a main ingredient in salads. It is widely grown commercially under greenhouse and hydroponic conditions (Lee et al., 2005; Park and Lee, 2006). In 2011, in Korea, there were more than 4,691 ha of leaf lettuce grown in both greenhouse and in open field with an estimated economic value of USD 376 million.

Lettuce cultivars are host for 17 kinds of plant pathogens, such as gray mold, downy mildew, sclerotinia rot, powdery mildew, bottom rot, phytophthora rot, fusarium wilt, soft rot, bacterial spot, lettuce mosaic virus, and leaf yellowing. These diseases resulted to the loss of lettuce crops worth millions of dollars throughout the world every year (Cho et al., 1997; Davis et al., 1997).

Gray mold caused by the fungus $B$. cinerea has been considered as a major disease in greenhouse-grown lettuce. The romaine lettuce variety and some iceberg lettuce are susceptible to $B$. cinerea in infected fields. The occurrence of gray mold is most prevalent during cold season from February to April (Cho et al., 1997; Shin et al., 1991).

$B$. cinerea can survive on plant debris, as secondary inoculum on numerous crops and weed hosts, and as sclerotia in soil. Airborne conidia rapidly germinate and colonize target tissue and damaged lettuce stems and older leaves (Cho et al., 1997; Davis et al., 1997; Shin et al., 1991). Initially, the infected area appears to be water soaked, and as the infection progresses the lesion color changes from brown to gray. The disease can spread from the leaves to the stem and, affected areas rapidly turn soft and rotten. On the other hand, the gray fuzzy mycelium that is usually seen on gray mold infected plants may not always be present on lettuce (Guillem et al., 2007).

Chemical fungicides can provide excellent control of some pathogens, however, fungicide resitance might occur when expected levels of disease control are no longer achieved with the recommended dose. Benzimidazole and $N$-phenylcarbamate fungicides have caused the emergence of multi-resistant $B$. cinerea, known to be distributed 
worldwide including Korea (Lim et al., 2006; Ma et al., 2007) and laboratory mutants resistant to QoIs were recently isolated and characterized in Japan (Banno et al., 2009). Facility cultivation had increased, and with the emergence of fungicide-resistant isolates of $B$. cinerea, eco-friendly pest management measures are needed (Lim et al., 2006).

This study aimed to identify resistant accessions from lettuce germplasm used in the leaf lettuce production system, and to breed new cultivars resistant to gray mold. Field and greenhouse assays were developed and compared in determining whether greenhouse assays could be productively used for cost efficient screening of resistant germplasm.

\section{Diversity of 212 accessions of lettuce germplasm}

Cultivated lettuce cultivars are classified into horticultural types based on head leaf shape, size, and texture. The genus Lactuca comprises about 100 species; however, the number of taxa differs from one author to another. Considerable progress in both fundamental research on Lactuca germplasm and its practical applications has been achieved during the last 25 years in the U.S.A. Cultivated lettuce and wild lettuce are infecsted by the same insect pests and diseases (Lebeda et al., 2007).

The National Agrobiodiversity Center (NAC) of the Rural Development Administration (RDA), Korea provided the 212 accessions of lettuce germplasm which were introduced from 35 countries (Table 1). The 212 accessions of lettuce germplasm consisted of five species: $L$. sativa (193), L. sativa var. longifolia (2), L. sativa var. crispa (2), L. saligna (2), and L. serriola (1). Looseleaf-lettuce is a main leaf type of lettuce germplasm and accounted for $63.7 \%$ of the total tested lettuce germplasm (Table 1).

To cope with the insect pests and diseases affecting lettuce, plant breeders constantly introduced improved lettuce varieties. Among the improved varieties, L. serriola was found to be resistant to downy mildew, corky root and big vein; and $L$. saligna variety was found to be resistant to looper, downy mildew, infectious yellow, and cucumber mosaic. $L$. virosa has been used in lettuce breeding to obtain cultivars with improved color, root system, and texture (McGuire et al., 1993). Some species in the lettuce's gene pool, L. serriola, L. saligna and $L$. virosa, are weedy and occurred on waste places and habitats (Lebeda et al., 2004, 2007)

\section{Preparation of lettuce seedlings and inoculation of pathogen}

Twenty seeds of each tested accession were replicated and disinfected with $2 \% \mathrm{NaOCl}$ for two hours. Disinfected seeds were washed with tap water three times before pregerminating on moist filter paper in Petri-dishes at $25^{\circ} \mathrm{C}$ for one-week in dark condition. Eighteen seeds of pregerminated lettuce germplasm were sowed into 120 holes plug pots filled with peat moss as an artificial soil. The lettuce seedlings were grown for 70 days in the green-house and were watered every other day. None of the lettuce germplasm was sprayed with fungicides.

The gray mold pathogen, B. cinerea (KACC40573) was obtained from the Korea Agricultural Culture Collection (KACC) of the RDA. The artificial inoculum method of $B$. cinerea as reported by Choi et al. (2009) was modified. One mycelial plug ( $6 \mathrm{~mm}$ diameter) was taken from an actively growing culture of $B$. cinerea on Potato Dextrose Agar medium (PDA; $200 \mathrm{~g}$ potato, $20 \mathrm{~g}$ dextrose, and $17 \mathrm{~g}$ agar in $1 \mathrm{~L}$ distilled water). Each plug was placed at the center and grown on PDA at $20^{\circ} \mathrm{C}$ for five days. To induce conidia spores, an agar plate with fungal hyphae was placed under florescent light for 24 hours. The conidia suspensions were prepared from seven-day-old PDA cultures by dislodging spores from the surface of the cultures with a sterile paint brush in sterile distilled water. Then, the concentration of

Table 1. Origin and characteristics of 212 accessions of lettuce germplasm

\begin{tabular}{llll}
\hline Species & Origin & Leaf type & Variety \\
\hline & USA (34), Korea (32), Netherlands (27), Russia (19), & & \\
& Bulgaria (13), Canada (9), United Kingdom (9), Spain (5), & Looseleaf (135), & Cultivar (120), \\
Lactuca sativa (193), & China (4), Japan (4), Malaysia (3), Italy (3), & Butterhead (27), & Local (49), \\
L sativa var. longifolia (2), & Germany (3), Ukraine (2), Portugal (2), Hungary (2), France & Romain (18), & Inbred line (18), \\
L sativa var. crispa (2), & (2), Costa Rica (2), Australia (2), Vietnam (1), Uzbekistan & Crisphead (16), & Hybrid (2), \\
L saligna (2), & (1), Uruguay (1), Thailand (1), Switzerland (1), Poland (1), & Iceberg (14), & Wild (2), \\
L serriola (1), & Mexico (1), Laos (1), Kazakhstan (1), Israel (1), Iran (1), & Hybrid (2), & Unknown (21) \\
Unknown (12) & Egypt (1), Czechoslovakia (1), Cuba (1), Brazil (1), & Prickly (1) & \\
& Unknown (19) & & \\
\hline
\end{tabular}


conidia suspensions was adjusted to the $3 \times 10^{7}$ conidia $/ \mathrm{ml}$ by a hemacytometer.

\section{Disease evaluation on biological assay}

70 days old seedlings of 212 accessions of lettuce germplasm were tested with 15 replicators and inoculated with conidial suspension $\left(3 \times 10^{7}\right.$ conidia/ml $)$ of $B$. cinerea. Gray mold disease caused by $B$. cinerea could appear on plants at all stages although initial infection often occurs at the seedling stage in the greenhouse. The temperature in the bad was initially set to $18-21^{\circ} \mathrm{C}$ with saturated humidity at one days after inoculations. Then the temperature range was

Disease incidence $(\%)=$

$$
\frac{\text { Total number of infected plants }}{\text { Total number of examined plants }} \times 100
$$

lowered to $18-24^{\circ} \mathrm{C}$ and relative humidity was maintained $90 \%$ at 28 days after inoculations for the duration of gray mold disease. The experiment was conducted twice in a completely randomized design. It is known that the gray mold pathogen infest of plant cell walls, disintegrating the quality of pectin pectinase secretion (La et al., 1994). Lettuce seedlings appeared to be damping off, while older plants rot at the stem or on lower leaves in contact with the soil. Usually, high humidity promotes $B$. cinerea activity, which cause blight or rotting of leaves, flowers and fruits at all stages of maturity (Slowley et al., 2010).

Disease severity was determined for 28 days with seven days interval after the inoculation of conidia suspension. We assessed the severity of gray mold rot symptoms by assigning symptom grades based on visual inspection, as well as by measuring healthy and diseased root tissues. The visible symptoms that appeared sequentially were crown rot, stem lesions, plant wilt, leaf defoliation, and dampingoff. The disease incidence of each tested accession of lettuce germplasm was determined using the following formula.

$B$. cinerea gray mold disease resistance level was graded with the disease incidence: Resistant denotes $0 \%$ of disease incidence, moderate resistance denotes less than $20 \%$ of disease incidence, susceptible denotes $20.1 \%$ to $80.0 \%$ of disease incidence, and highly susceptible signifies $80.1 \%$ or higher of disease incidence (Table 2).

Table 2. Evaluation of resistance against gray mold disease, caused by Botrytis cinerea, among 212 accessions of the lettuce germplasm

\begin{tabular}{lccccc}
\hline \multirow{2}{*}{ Level of resistance } & Disease incidence & \multicolumn{4}{c}{ No. of accession in lettuce germplasm } \\
\cline { 3 - 6 } & $(\%)$ & 7 days & 14 days & 21 days & 28 days \\
\hline Resistant & 0 & 4 & 3 & 3 & 3 \\
Moderately resistant & $0.1<=20.0$ & 54 & 1 & 1 & 1 \\
Susceptible & $20.1<=80.0$ & 154 & 208 & 76 & 0 \\
Highly susceptible & $80.1<=100$ & 0 & 0 & 132 & 208 \\
\hline
\end{tabular}

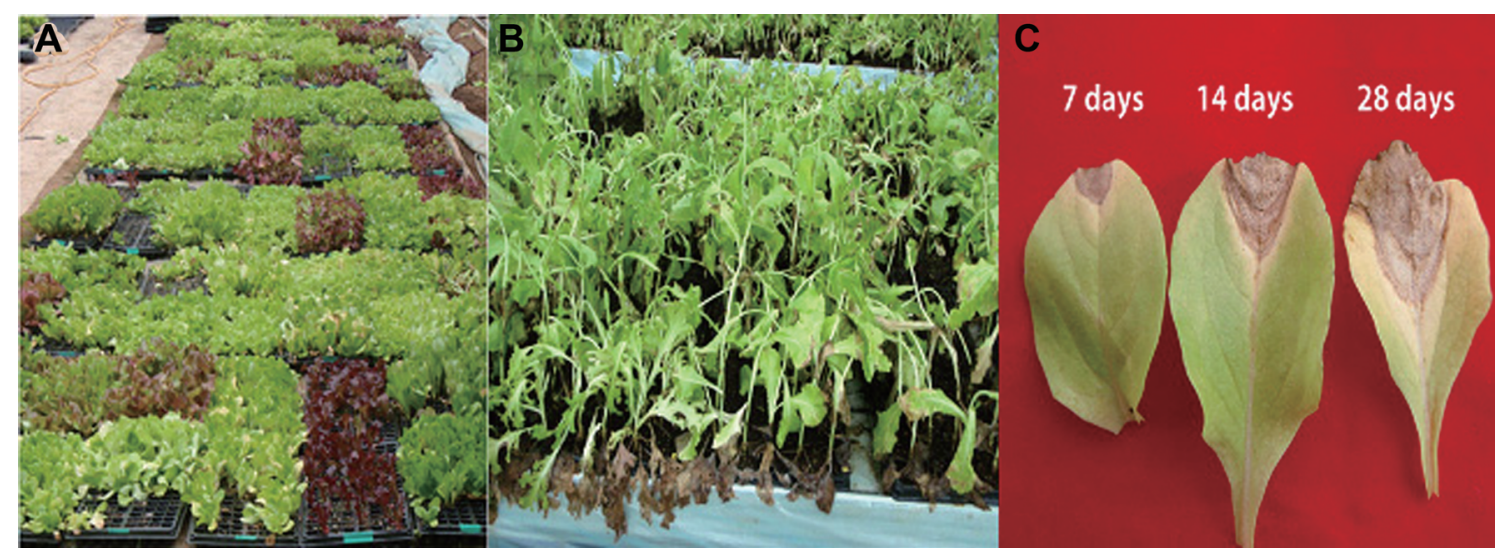

Fig. 1. Photographs show the preparation of lettuce seedlings (A) and the occurrence of gray mold caused by Botrytis cinerea after inoculation $(\mathrm{B}, \mathrm{C})$. 


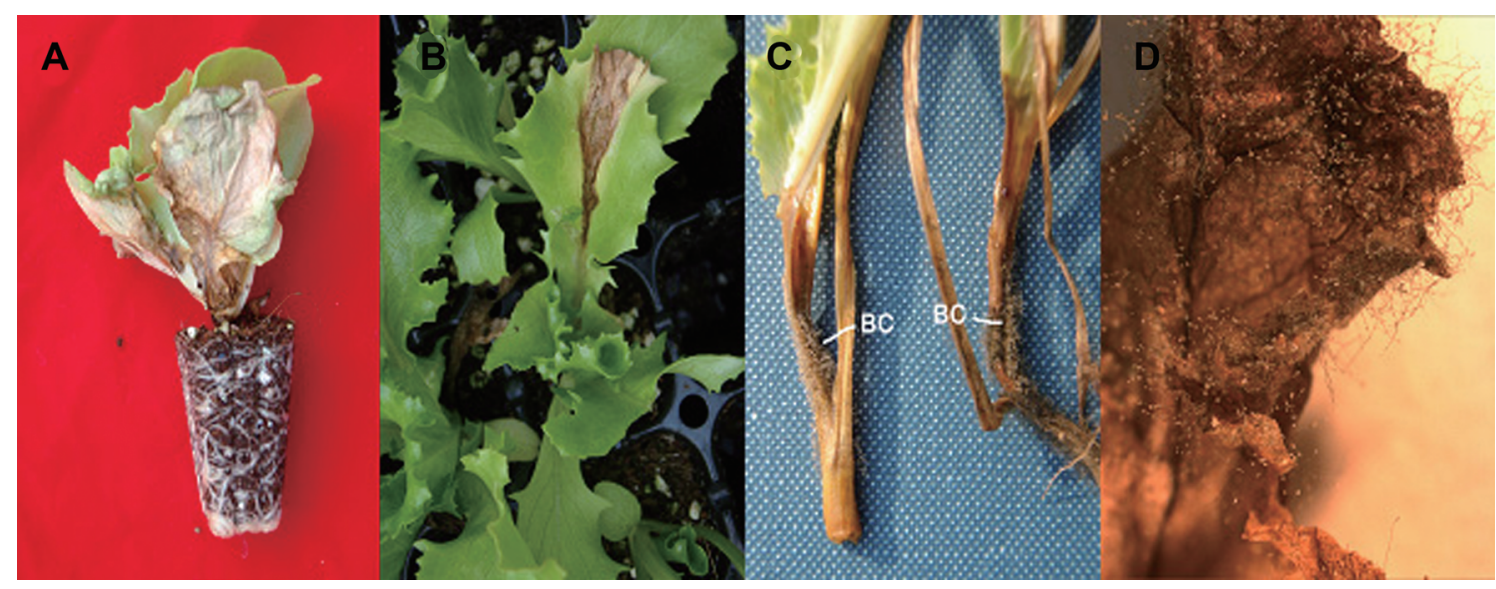

Fig. 2. Occurrence of gray mold disease symptoms caused by Botrytis cinerea after artificial inoculation (A, B). Sporulation of $B$. cinerea $(\mathrm{BC})$ was observed on rotted stem and leaves $(\mathrm{C}, \mathrm{D})$.

Table 3. Attributes of four accessions of candidate gray mold resistant germplasm

\begin{tabular}{ccccccc}
\hline IT Number & Species & Accession name & Origin & Leaf type & Variety $\begin{array}{c}\text { Disease incidence* } \\
(\text { Mean } \pm \text { SD, } \%)\end{array}$ \\
\hline 908801 & Lactuca sativa & 100 & Uzbekistan & Looseleaf & Cultivar & $20.0( \pm 2.1)$ \\
K021055 & Lactuca sativa & NAPKOR & Hungary & Looseleaf & Cultivar & $20.0( \pm 1.2)$ \\
K000598 & Lactuca saligna & 1625 & U.S.A. & Looseleaf & wild species & $0.0( \pm 0.0)$ \\
K000599 & Lactuca saligna & 1629 & U.S.A. & Looseleaf & wild species & $0.0( \pm 0.0)$ \\
\hline
\end{tabular}

*At 35 days after inoculation with $3 \times 10^{7}$ conidia/ml of Botrytis cinerea.

Lettuce infected with $B$. cinerea started to wilt, lower leaves, turned yellow to brown, and then the entire plant totally dried up. The primary symptoms of the gray mold disease include wilting of plant accompanied by a fuzzy gray sporulation at the plant base, which contains masses of conidia of $B$. cinerea. Sclerotia may also be present on infected tissue in the later part (Cho et al., 1997; Davis et al., 1997).

At 7 days after inoculation of $B$. cinerea, water soaked disease symptoms in leaf began to appear in susceptible lettuce germplasm. Among the 212 accessions of lettuce germplasm, 80 accessions were onserved to be highly susceptible with $47.0 \%$ disease incidence in leaves, while seven accessions of lettuce germplasm had $13.0 \%$ disease incidence or no symptoms (Table 2, Fig. 1).

At 14 days after inoculation, 63 (29.7\%) accessions of lettuce germplasm had less than $47.0 \%$ of disease incidence; while 149 susceptible accessions of lettuce germplasm had more than $53.0 \%$ of disease incidence (Table 2). Two of 149 accessions of lettuce germplasm, loose-leaf (IT K151567) and butterhead (IT K153764) were highly susceptible with more than $80.0 \%$ of disease incidence and had symptoms such as brown or tan lesions with darker halo, plant wilt, and leaf defoliation (Fig. 2).
At 21 days after inoculation, three accessions of lettuce germplasm showed resistance and one accession showed moderate resistance to $B$. cinerea. Almost 208 susceptible accessions of lettuce germplasm had having more than $67.0 \%$ of disease incidence (Table 2).

At 28 days after inoculation, only one accession of lettuce germplasm, L. sativa (K021055) was found to be high moderatly resistant and scored less than $20 \%$ of disease incidence to $B$. cinerea. Three accessions of lettuce germplasm, L. sativa (IT908801), L. saligna (K000598), and L. saligna (K000599) proved to be resistant to gray mold disease. Almost 208 accessions were shown to be highly susceptible and scored $100.0 \%$ of disease incidence (Table 3, Fig. 3). Leaves and stems on or near the soil turned light brown and develop gray or brown fuzzy growth of fungal spores. Infected plants wither and rot and often develop flattened hard black masses, called sclerotia, under rotted parts (Fig. 1).

At 35 days after inoculations, two resistant germplasm (K000598 and K000599) classified as L. saligna showed $100 \%$ resistance two L. sativa (IT908801 and K021055) showed $80 \%$ resistance (Table 3). L. saligna is a weed by characteristic found in both lowland and highland areas and is widely distributed over the Mediterranean Basin 


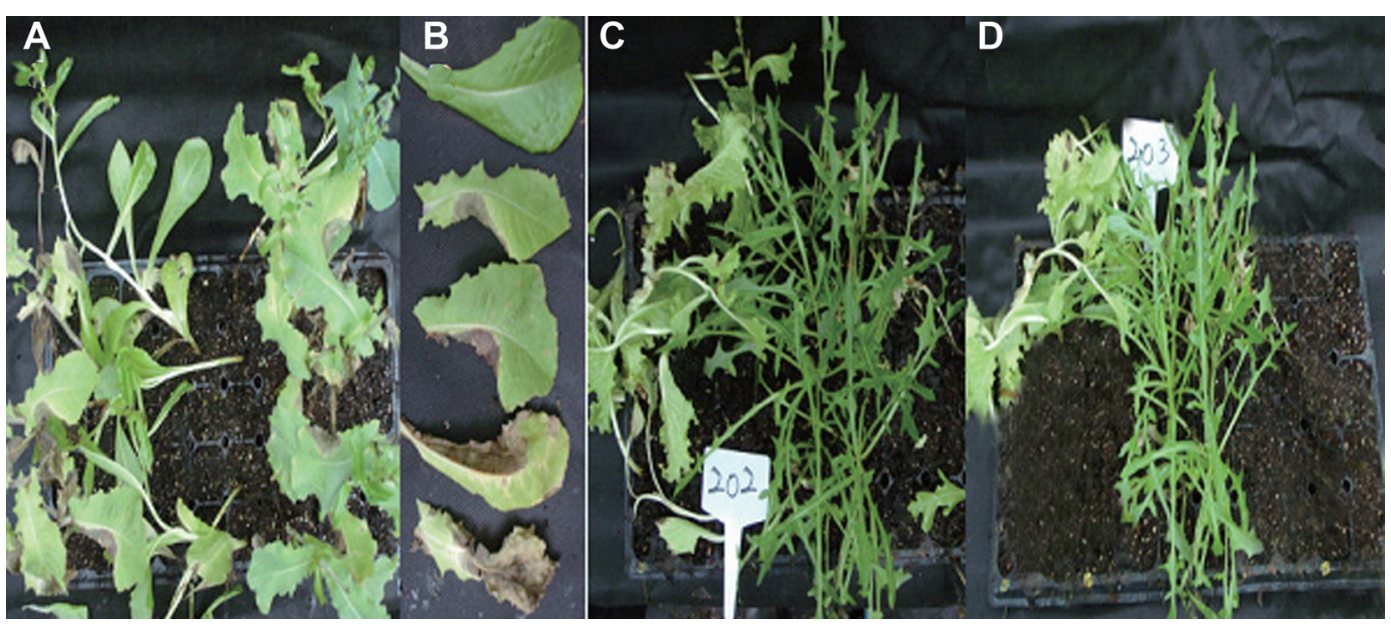

Fig. 3. Comparison of susceptible accession (A, B) and resistant accession, (C, D) of lettuce germplasm against gray mold at 28 days after inoculation with $3 \times 10^{7}$ conidial suspension of Botrytis cinerea.

and extends to the Caucasus and to Europe as far as Central Germany and Southern Russia (Cvelev, 1989). This species is currently considered to be the most important source of highly resistant and non-host specific lettuce germplasm (Lebeda and Zinkernagel, 2003; Peteželová et al., 2007).

We have been able to estimate a biological assay of the resistance of lettuce germplasm to B. cinerea. Among the 212 accessions of lettuce germplasm, 208 accessions (98.0\%) scored $100 \%$ disease incidence of gray mold at 35 days after inoculation. Only four accessions of lettuce germplasm showed resistance to gray mold disease at 35 days after inoculation. Fortunately, two gray mold resistant germplasm classified as L. saligna exhibited $100 \%$ disease resistance.

The necrotrophic fungi, Sclerotinia sclerotiorium and $B$. cinerea secrete oxalic acid as a pathogenicity factor. Unger et al. (2005) showed that the aggressiveness of $B$. cinerea is linked to an oxidative burst-suppressing agent that suppresses HR. The precise role of $\mathrm{HR}$ in the interaction between $B$. cinerea and its hosts thus remains to be elucidated. Interestingly, on wild type Arabidopsis plants, the oxalate-degrading bacteria can reduce $B$. cinerea symptoms by more than $50 \%$ (Schoonbeek et al., 2007). Furthermore, plants expressing a fungal cutinase targeted to the cell wall show a strong resistance to the soft rot pathogen B. cinerea compared to wild types (Chassot et al., 2007). Finally, Chen et al. (2013) showed that overexpression of AtWRKY28 and AtWRK75 induced oxidative burst in host plants, which suppressed the hyphal growth of $S$. sclerotiorum, and consequently inhibited fungal infection.

This study revealed that the four candidate accessions could be used as breeding sources for the gray mold resistance lettuce breeding program. Also, further genetic studies should be carried out to verify the results of this study with the overall focus of providing information on important characteristics of lettuce germplasm in the interest of safe agriculture production and eco-friendly organic farming.

\section{Acknowledgments}

This study was carried out with the support of "Cooperative Research Program for Agricultural Science \& Technology Development (Project No. PJ00912704), Rural Development Administration, Republic of Korea.

\section{References}

Banno, S., Yamashita, K., Fukumori, F., Okada, K., Uekusa, H., Takagaki, M., Kimura, M. and Fujimura, M. 2009. Characterization of QoI resistance in Botrytis cinerea and identification of two types of mitochondrial cytochrome b gene. Plant Pathol. 58:120-129.

Chassot, C., Nawrath, C. and Metraux, J. P. 2007. Cuticular defects lead to full immunity to a major plant pathogen. Plant J. 49:972-980.

Cho, W. D., Kim, W. G., Jee, H. J., Choi, H. S., Lee, S. D. and Choi, Y. C. 1997. Compendium of vegetable diseases with color plates. p 447. NIAST, Suwon, Korea.

Cvelev, N. N. 1989. Flora Partis Europae URSS. Vol. 8. Nauka, Leningrad, Russia.

Davis, R. M., Subbarao, K. V., Raid, R. N. and Kurtz, E. A. 1997. Compendium of Lettuce Diseases. St. Paul, MN, APS Press, USA.

Guillem, S., Eva, C., Celia, B., Mannuel, A. and Isabel, T. 2007. The suppressive effects of composts used as growth media against Botrytis cinerea in cucumber plants. J. Eur. Plant Pathol. 117:393-402.

Hornby, D. 1990. Biological control of plant-parasitic nematodes: 
an ecological perspective, a review of progress and opportunities for further research. In: Biological control of plant-parasitic nematodes eds. K. Davies and Y. Spiegel. pp. -38. SpringerVerlag, Berlin, Germany.

La, Y. J., Kim, J. W., Chung, Y. R., Huh, N. E. and Cho, K. Y. 1994. Partial purification and properties of polygalacturonase produced by Botrytis cinerea. Kor. J. Plant Pathol. (in Korean) 10: 215-221.

Lebeda, A. and Zinkernagel, V. 2003. Characterization of new highly virylent German isolates of Bremia lactucae and efficiency of resistance in wild Lactuca spp. germplasm. J. Phytopathol. 151:274-282.

Lebeda, A., Doležzlová, I., Kř́istková, E., Dehmer, K. J., Astley, D., Van de Wiel, C. C. M. and Van R. Treuren. 2007. Acquisition and ecological characterization of Lactuca serriola $\mathrm{L}$ germplasm collected in the Czech Republic, Germany, the Netherland and United Kingdom. Genet. Resour. Crop Evol. 54:555-562.

Lebeda, A., Doležzlová, I., Feráková, V. and Astley, D. 2004. Geographical distribution of wild Lactuca spp (Asteraceae, Lactucaeae). Bot. Rev. 70:328-356.

Lee, J. S., Choi, J. W., Chung, D. S., Lim, C. I., Seo, T. C., Do, G. L. and Chum, C. H. 2005. Effects of lettuce (Lactuca sativa L) cultivars and cultivation methods on growth, quality, and shelf-life. Kor. J. Hort. Sci. Technol. 23:12-18.

Lim, T. H., Kim, J. H. and Cha, B. 2006. Responses of peach blossom blight and brown rot fungus Monilinia fructicola to benzimidazole and diethofencarb in Korea. Plant Pathol. J. 22:1-6. .

Ma, Z., Yan, L., Luo, Y. and Michailides, T. J. 2007. Sequence variation in the two-component histidine kinase gene of Botrytis cinerea associated with resistance to dicarboximide fungicides. Pesti. Biochem. Physiol. 88:300-306.

McGuire, P. E., Ryder, E. J., Micheimore, R.,W. Clak, R. L., Antle, R., Emery, G., Hannan, R. N., Kesseli, R. V., Kutz, E. A., Ochoa, O., Rubatzky, V. E. and Waycott, W. 1993. Genetic resources of Lettuce and Lactuca species in California. An Assessment of the USDA and UC collections and recommendations for long-term security Report No. 12, Resources Conservation Program University of California, Davis, California, USA.

Park, K. W. and Lee, J. M. 2006. Wrap-ups, A unique method of vegetable usage and consumption in Korea. Chronica Hort. 46:13-15.

Petrželová, I., Lebeda, A., Nevo, E. and Beharav, A. 2007. Variation of response against Bremia lactucae in natural populations of Lactuca saligna, pp. 169-173 In: A. Lebeda, P.T.N. SpencerPhillips (eds). Advances in downy mildew research, vol. 3. Proceeding of the 2nd international downy mildews symposium, Palacký University in Olomouc and JOLA, VOS, Kostelec Na Hané, Czech Republic.

Schoonbeek, H. J., Jacquat-Bovet, A. C., Mascher, F. and Métraux, J. P. 2007. Oxalate-degrading bacteria can protect Arabidopsis thaliana and crop plants against Botrytis cinerea. Mol. PlantMicrobe Interact. 20:1535-1544.

Seaman, A., Abawi, G., Gugino, B. K., Helms, M., Rangarajan, A., McGrath, M., Mohler, C. L., Tingey, W. M., Thomas, M. G., Kirkwyland, M. and Zuefle, M. 2012. 2012 production guide for organic lettuce. Cornell University Cooperative Extension NY, USA.

Shin, D. B., Kim, D. K. and Jung, Y. T. 1991. Study on the occurrence of lettuce gray mold disease, cultural characteristics and efficiency of chemical control under controlled cultivation conditions in drained paddy field. Res. Rept. RDA (CP) 33:15.

Slowley, E. N. K., Dewey, F. M. and Shaw, M. W. 2010. Persistent, symptomless, systemic, and seed-borne infection of lettuce by Botrytis cinerea. Eur. J. Plant Pathol. 126:61-71.

Unger C., Kleta, S., Jandl, G. and von Tiedemann, A. 2005. Suppression of the defense-related oxidative burst in bean leaf tissue and bean suspension cells by the necrotrophic pathogen Botrytis cinerea. J. Phytopathol. 153:1-12. 